\title{
Effect of pressure and temperature of devolatilisation on the morphology and steam gasification reactivity of coal chars
}

\author{
J. Fermoso, M.V. Gil, A.G. Borrego, C. Pevida, J.J. Pis, F. Rubiera* \\ Instituto Nacional del Carbón, CSIC, Apartado 73, 33080 Oviedo, Spain
}

\begin{abstract}
The effect of operating conditions (pressure and temperature) on char morphology and structure during coal devolatilisation was studied. For this purpose, five different rank coals were selected: a lignite, three bituminous coals and a semi-anthracite. The coal chars were prepared by devolatilisation in a novel pressurised fixed-bed reactor. The pyrolysis experiments were carried out isothermally at temperatures of 800,900 and $1000{ }^{\circ} \mathrm{C}$, and pressures of 1, 5, 10 and $20 \mathrm{~atm}$. The chars obtained from the bituminous coals at elevated pressure experienced a high degree of swelling, whereas those from the lignite and semianthracite were hardly affected at all by pressure. The devolatilisation temperature did not appear to have any significant effect on char morphology below $1000{ }^{\circ} \mathrm{C}$. The reactivity of the char samples prepared under different pyrolysis conditions was studied by isothermal thermogravimetric analysis at $1000{ }^{\circ} \mathrm{C}$ under a steam atmosphere. The chars obtained at elevated pressure were found to be more reactive than those produced at atmospheric pressure, and this difference was greater in the case of the bituminous coals. An increase in pyrolysis temperature led to a decrease in char reactivity.
\end{abstract}

Keywords: Coal rank; pyrolysis pressure; pyrolysis temperature; char morphology; steam gasification

\section{Introduction}

Coal can be expected to play an important role in catering for the world's energy needs in view of the current rate of energy consumption, and an even larger role if the global energy demand continues to rise in the next few decades ${ }^{1}$. However, the demand for energy is accompanied by an increasing concern for the environment due to the $\mathrm{CO}_{2}$ emissions from fossil fuel utilisation. The development and deployment of clean coal technologies with higher efficiencies will

\footnotetext{
* Corresponding author. Tel.: +34 985118 975; Fax: +34 985297662

E-mail address: frubiera@incar.csic.es (F. Rubiera)
} 
therefore be essential in the future in order to minimise the environmental impact of coal utilisation. Several technologies, such as Integrated Gasification Combined Cycle (IGCC) and Pressurised Fluidised Bed Combustion (PFBC), have been found to be the most viable alternatives for the clean utilisation of coal due to their use of combined cycles. Higher operating pressures can be applied in these technologies: for example, 10-15 atm for PFBC, and 15-25 atm for IGCC. These technologies provide several advantages over the conventional coal firing processes, including an increase in coal throughput, a reduction in pollutant emission and an enhancement in the intensity of reactions ${ }^{2,3}$.

The coal gasification process consists in the rapid devolatilisation and subsequent heterogeneous gasification of the resultant char. While volatile matter is being released during the devolatilisation process, the physical structure of the coal char particles may change significantly. Some coals exhibit thermoplastic behaviour when heated and these coals melt to form a highly viscous liquid. Usually, bituminous coals with a carbon content in the range of 81-92\% exhibit maximum fluidity. These coals experience significant changes in their pore structure during devolatilisation and generate a solidified char with well-ordered anisotropic domains. Anthracites, subbituminous coals and lignites exhibit limited or negligible thermoplastic behaviour. In the case of lignites and subbituminous coals the carbonaceous material exhibits a disordered and highly porous structure after devolatilisation, whereas in the case of anthracites the textural characteristics of the parent coal are essentially retained ${ }^{4}$. Thus, it is the characteristics of the resultant char that control the subsequent gasification process. For example, the morphology of the char determines its aerodynamic behaviour in reactors such as entrained-bed gasifiers ${ }^{5}$. Char morphology depends on the rank and petrographic composition of the parent coal, as well as on the experimental conditions.

The effect of pressure on the behaviour of coal during devolatilisation has attracted widespread attention in recent years due to the development of pressurised facilities for coal utilisation such as IGCC and pressurised fluidised bed combustion (PFBC) ${ }^{6,7}$.

The aim of the present work is to study the effect of pressure and temperature on the devolatilisation behaviour of coals which range in rank from lignite to anthracite and have different maceral composition. The aspects considered cover morphology, textural parameters and high temperature isothermal reactivity, which are relevant parameters for understanding the pressurised gasification of coal. 


\section{Experimental}

\subsection{Coal samples}

Five coals of different rank $^{8}$ were selected for this study: a lignite (LT), three bituminous coals with low (DI) and high (SA and DT) volatile matter contents, respectively, and a semianthracite (HV). These materials were ground and sieved to obtain a fraction with a particle size of 75-150 $\mu \mathrm{m}$. The rank of a coal can be determined from the reflectance of the vitrinite, which is related to the $\mathrm{C} / \mathrm{H}$ and $\mathrm{C} / \mathrm{O}$ ratios and volatile matter ${ }^{9}$.

\subsection{Char preparation}

The chars were produced by devolatilisation of the raw coals in a novel pressurised fixed-bed reactor (PFB), whose schematic flow diagram is shown in Fig. 1. Details of the experimental device are given elsewhere ${ }^{10}$. Briefly, it consists of a stainless steel SS310 tubular reactor (13 $\mathrm{mm}$ internal diameter, $305 \mathrm{~mm}$ height) with a porous plate, which is able to work at a maximum pressure of $20 \mathrm{~atm}$ at $1000{ }^{\circ} \mathrm{C}$. Coal particles are fed into the system from a pressurised hopper. The mass flow rate of the solids is controlled using a pneumatically actuated three-way valve, which discharges the sample into the reactor in a semi-continuous mode, since the time interval between discharges can be fixed. In this way, the calculated heating rate for the particles was approximately $5000^{\circ} \mathrm{C} \mathrm{s}^{-1}$. The char particles are then collected on a porous plate inside the reactor. The total duration of the experiment was 10 min. The reactor thermocouple is in contact with the sample bed. The pressure is measured by a pressure transducer and automatically controlled by a micro-valve.

The pyrolysis tests were carried out isothermally at temperatures of 800,900 and $1000{ }^{\circ} \mathrm{C}$, and at pressures of 1, 5, 10 and $20 \mathrm{~atm}$. A total gas flow rate of $300 \mathrm{NmL} \mathrm{min}^{-1}$ was used; 3 vol. \% oxygen was added to the nitrogen stream in order to burn the released volatiles and to prevent the formation of soot. The chars were denoted by coal acronyms followed by the pyrolysis conditions, e.g., SA1000-1 stands for the char obtained from coal SA, at $1000^{\circ} \mathrm{C}$ and $1 \mathrm{~atm}$.

\subsection{Char characterisation}

Chars produced in the PFB were analysed for proximate and ultimate analyses and to determine the char density. The external morphology of the coal chars was observed by means of scanning electronic microscopy (SEM). In addition, the optical texture of the char material was examined under a polarised reflected light microscope with oil immersion objectives of 20x and 50x magnification, partially crossed polars, and a $1 \lambda$ retarder plate. For this purpose, 
the chars were embedded in an epoxy resin, left overnight and then cut and polished for microscopic examination of the particle cross-sections. Optical microscopy is a versatile tool for the study of the structural organisation of char material, since this technique enables the analyst to distinguish and quantify the isotropic (disordered) and anisotropic (ordered) char materials formed after the coal has passed through a thermoplastic stage.

The micropore surface area of the chars was determined from the nitrogen adsorption isotherms at $-196^{\circ} \mathrm{C}$, which were obtained using a Micromeritics ASAP 2010M instrument. The Dubinin-Asthakov method was applied to the $\mathrm{N}_{2}$ adsorption isotherms in order to obtain the corresponding micropore volume, which was then used to calculate the micropore surface area of the chars ${ }^{11}$.

The helium density measurements of the raw coals and chars were performed on a helium pycnometer (Micromeritics, Accupyc 1330). The particle bulk densities were also determined using a tap density procedure by means of which the weights and volumes of the char samples were measured in a graduated cylinder. In this procedure, the outside of the cylinder is tapped until the particles have settled, after which their volumes are recorded. Data are obtained for the different amounts of char added to the tube. Finally, the weight of the particles versus the volume they occupy is plotted on a graph. The slope of the line corresponds to the bulk density of the char in the cylinder ${ }^{12}$.

\subsection{Char gasification}

Thermogravimetric analysis (TGA) is one of the most common techniques available for rapidly investigating and comparing thermal events and kinetics during the pyrolysis, combustion and gasification of solid raw materials ${ }^{13-15}$. The gasification of the coal chars, produced by devolatilisation in the PFB reactor, was carried out under isothermal conditions at atmospheric pressure in a thermobalance (Setaram TAG24). Approximately $5 \mathrm{mg}$ of sample was deposited in a crucible with a circular base $(5 \mathrm{~mm}$ diameter and $2 \mathrm{~mm}$ height). A thermocouple was located close to the platinum basket to monitor the temperature and to close the oven control loop.

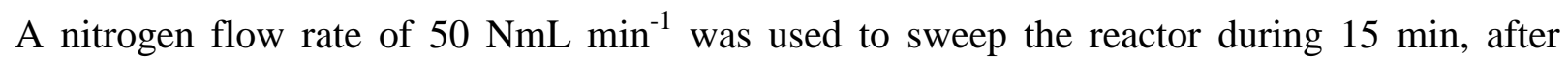
which the temperature was increased from room temperature to $1000{ }^{\circ} \mathrm{C}$ at a heating rate of 50 ${ }^{\circ} \mathrm{C} \min ^{-1}$, this temperature being maintained for another $15 \mathrm{~min}$. Next, char gasification was initiated by switching to $30 \mathrm{vol} . \% \mathrm{H}_{2} \mathrm{O}_{\mathrm{v}}$ and $70 \mathrm{vol} . \% \mathrm{~N}_{2}$ at a total flow rate of $150 \mathrm{NmL} \mathrm{m^{-1 }}$. The sample was then allowed to react until completion. The steam generator consisted of a 
$\mathrm{CEM}^{\circledR}$ (Controlled Evaporator and Mixer), in which water and $\mathrm{N}_{2}$ were mixed and heated up to the desired temperature $\left(150^{\circ} \mathrm{C}\right)$. Liquid and gas mass flow controllers were used to control the flow rates of the water and nitrogen, in order to ensure that the desired steam concentration remained constant.

\section{Results and discussion}

\subsection{Characteristics of the parent coals and chars}

The chemical (proximate and ultimate analysis) and petrographic characteristics of the raw coals are summarised in Table 1. It can be seen that the chemical analysis data follow the expected trends with rank, i.e., a decrease in volatile matter, hydrogen and oxygen contents and an increase in carbon content and vitrinite reflectance with increasing coal rank. Table 1 also shows that vitrinite is the main maceral group of the lignite (LT), and the two highest rank coals, the semi-anthracite (HV) and low volatile coal (DI), while inertinite is the main maceral group of the two high volatile bituminous coals (DT and SA). Although inertinite contains a lower amount of volatile matter than vitrinite (of the same coal) up to the anthracite rank $^{16}$, semi-fusinite, which is the main inertinite in all the coals, is a maceral that has undergone mild to moderate alteration prior to burial, as a result of which it retains a certain plasticity. Data in Table 1 show that the volatile matter content of the two hvb inertinite-rich coals (DT and SA) is around 12 points lower than that expected for vitrinite-rich coals with a similar vitrinite reflectance ${ }^{17}$.

Table 2 contains the results of the proximate and ultimate analyses, and the densities of the coal chars produced in the PFB. The effect of operating conditions on char characteristics will be discussed in the following sections, and only a comparison between the parent coals and the chars devolatilised at atmospheric pressure will be considered here. The devolatilised chars are significantly enriched in carbon compared to the parent coals, although there is no clear trend to suggest that carbon-richer coals yield carbon-richer chars. Indeed the hvb Chinese coal (DT) and the lvb coal (DI) yielded the chars with the highest carbon content. The efficient devolatilisation of both coals is also shown by the relatively low residual volatiles in the chars once expressed on a dry-ash-free basis. The bulk and Helium density of the coals (Table 1) vary within a relatively narrow interval and the differences between coals are obscured by the presence of mineral matter. Thus, lignite (LT) has the highest mineral matter content and true density, even though one would expect this coal to have the lowest density. Nevertheless, the data are still useful for indicating a significant increase in density with devolatilisation which is 
higher than that attributable to ash enrichment. The bulk density of the coal particles (Table 1) varies within a narrow interval $\left(0.752-0.832 \mathrm{~g} \mathrm{~cm}^{-3}\right)$, the largest variation corresponding to lignite. The bulk density of the chars (Table 2) is generally lower as one would expect for a material that has experienced different degrees of swelling. The lowest difference between coal and char bulk densities corresponds to anthracite (HV) and the largest difference to the coal with the highest plasticity (DI).

\subsection{Effect of pyrolysis pressure}

Thermoplastic properties. It has been established in the literature that pressure plays a key role in the formation of char in pressurised reaction systems ${ }^{18,19}$. In this work, the effect of pyrolysis pressure was studied by the devolatilisation of a high volatile bituminous coal (SA) at $1000{ }^{\circ} \mathrm{C}$ and at four different pressures (1, 5, 10 and $\left.20 \mathrm{~atm}\right)$. It can be seen from Table 2 that the chemical composition of the resulting chars is slightly affected by the devolatilisation pressure. An increase in pressure leads to a decrease in volatile matter, oxygen, hydrogen and nitrogen contents, and an increase in the carbon content (Table 2). This trend is in a good agreement with the data published in the literature regarding the effect of pressure on the total yield of volatile matter under various experimental conditions, which have been summarised by $\operatorname{Shan}^{20}$. After devolatilisation, the helium density of the chars increased by a factor of between 1.40 and 1.49 , due to the loss of almost all of their volatile matter and to the increase in their ash content (Table 2). However, the bulk density of the chars is found to be significantly lower than that of the raw coal (Table 1), a decrease of $31.6 \%$ being recorded for the SA1000-1 char; whereas even lower bulk density values were recorded for chars subjected to higher pressures. The results summarised in Table 2, show that the chars obtained at pressures above atmospheric have bulk densities that are 19.6, 25.8 and 28.7\% lower than that obtained at atmospheric pressure. This could be due to the swelling of the char particles, as will be discussed below.

The effect of pressure on the thermoplastic properties of coals as a function of rank is highly variable. It has been observed that pressure affects the swelling behaviour of some bituminous coals $^{21-23}$. Khan and Jenkins ${ }^{24}$ studied the thermoplastic properties of 24 coals. These authors found that for almost all coals, maximum swelling passed through a sharp maximum with the increase in pressure, although the pressure at which this maximum occurred could not be correlated with coal rank. However, the contraction parameter for all the coals increased with pyrolysis pressure. They also found that the softening temperatures of the coals may increase, 
decrease, or remain unchanged with an increase in pressure. In contrast, the resolidification temperatures rose with pressure, leading to an increase in the plastic range of the coals when pyrolysed under pressure ${ }^{24}$. The morphology and the physical structure of the char particles after devolatilisation are therefore strongly influenced by external pressure.

Fig. 2 shows, through SEM images, the external morphology of the char particles obtained by devolatilising coal SA at $1000{ }^{\circ} \mathrm{C}$ and at pressures of 1, 5, 10 and 20 atm. It can be observed that most of the particles of the SA1000-1 char retain the external angular outline of the parent coal. In addition, the mean particle size is smaller than that of chars produced under pressure. Above atmospheric pressure, two main types of particles are observed. Whereas some particles preserve the external angular outline, as in the case of SA1000-1, other particles have a more rounded shape, as can be seen in Fig. 2 where the magnified SEM images (50 $\mu \mathrm{m})$, show a certain swelling (SA1000-10 and SA1000-20). In addition, visual inspection of the particles in Fig. 2 indicates increasing swelling with increasing pressure from 1 to 10 atm, whereas any further pressure increase does not seem to increase the size of the particles. A similar result was found by Lee et al. ${ }^{22}$ and $\mathrm{Wu}$ et al. ${ }^{18}$ who reported a maximum in swelling at pressures of around $10 \mathrm{~atm}^{6}$.

Maceral effect on particle morphology. The appearance of these two major types of particles during the devolatilisation of coal at elevated pressure can be explained with the help of the cross-section photomicrographs of the particles. A number of classification methods for char particles of different physical structures have been proposed in the literature, some of which attempt to categorise char particles into different morphological structures with the help of image processing ${ }^{25-30}$. Most of the terms in these systems are based on the morphology of the particles (e.g. cenosphere and network) whereas others refer to melting behaviour (e.g. solid and mixed). Other systems such as the char texture system of the International Committee for Coal and Organic Petrology ${ }^{31}$ which focus on maceral origin and the plastic behaviour of the components have also been used to follow the transformations experienced by a coal in combustion reactors ${ }^{4}$.

The appearance of the particles observed by means of SEM in Fig. 2 can be explained by taking into consideration the thermal behaviour of the two major maceral constituents of the parent coal, vitrinite and inertinite. The particles that exhibit a rounded to spherical shape regardless of the pyrolysis pressure, show in cross section a cenospheric shape with large voids in the central part of the particle (cf. Fig. 3a). The particles which retain the angular outline of 
the parent coal, shown in Fig. $3 b$ are mainly derived from inertinite-rich particles and generally have small pores that are distributed throughout the particle or represent material with limited plasticity. The inherent heterogeneity of inertinite, in particular semi-fusinite and macrinite, which exhibit optical properties ranging between those of vitrinite and those of fusinite, results in a variety of plastic and devolatilisation behaviours ${ }^{32}$, which are difficult to systematise. The material derived from inertinite in the SA char ranges from fused porous isotropic material in network-like structures, typical of a devolatilised material with poor plasticity, to unfused isotropic material in solid unfused particles, which should be classified as Fusinoid or Inertoid according to Bailey et al. ${ }^{27}$. Particles consisting of porous anisotropic material that indicates rearrangement of the carbonaceous structure are also common in both network and mixed particles (Fig. 3b). The heterogeneity of inertinite behaviour and its capacity to form almost every known type of char, from Networks and Tenuispheres to Dense Solids has been largely acknowledged $^{28}$. In particular, high fusibility for inertinite has been reported in chars from Gondwana coals $^{18}$, with compositions close to the SA coal employed in the present study. In a study of the effect of pressure on the combustion behaviour of four Australian bituminous coals with different petrographic compositions, Benfell et al. ${ }^{33}$ claimed that inertinite was capable of exhibiting a fusibility as high as that of vitrinite under high pressure conditions. This behaviour, however, is not observed in the samples used in this work, in which the monomaceralic vitrinite particles consistently exhibited a higher plasticity and greater porosity than the inertinite-rich particles (see Fig. 3a and $\mathrm{b}$ for comparison).

The inertinite-rich char particles of SA exhibit large isotropic and some anisotropic domains, whereas some particles present mixed domains. Some particles also contain a significant amount of partially pyrolysed material. All of these features are observed in every char, to a larger or a lesser extent, irrespective of the pyrolysis pressure, and therefore the description of a trend for a variation in morphology and/or plastic behaviour in inertinite-derived material in SA char is difficult. Nevertheless, anisotropic porous inertinite-derived material tends to exhibit larger and more rounded pores with increasing pressure from 1 to $10 \mathrm{~atm}$, which suggest that plasticity is enhanced (Fig. 3b).

Another type of char particle which has a spherical-subspherical shape and rounded edges is also shown in Fig. 3. These particles, denoted by (a), are thought to derive from vitrinites and display an isotropic optical texture. Vitrinite in coal has a narrow interval of optical texture and behaves upon conversion in a relatively homogeneous way ${ }^{16}$ which is identifiable for any coal. The liberation of macerals upon grinding, which generates abundant monomaceralic vitrinite 
particles helps in the identification of the typical behaviour of vitrinite during processing for any given coal. At atmospheric pressure, vitrinite-derived chars present thick walls with a central pore surrounded by a thick and porous outer shell. An increase in the pyrolysis pressure caused these particles to swell, resulting in bigger central voids and thinner walls. In some cases, it even led to the fragmentation of swollen, very thin-walled particles ${ }^{33}$, as in the case of SA1000-10 and SA1000-20. However, fragmentation mainly affected the very thin-walled vitrinite-derived particles and, in these cases, the extent of swelling was difficult to assess.

The extent of coal swelling and the structure of the char particles formed after pyrolysis are determined by the internal pressure generated by the release of volatiles due to metaplast decomposition, the resistance to expansion induced by the shell (which is a function of its structural properties), and the external pressure on the particle ${ }^{18}$. High external pressure decreases the total volatile yields and enhances secondary tar reactions, which results in more low-molecular-weight volatile matter being retained in the char residue. The potential of a particle to swell then decreases, as does the release of volatiles due to the reduction in internal pressure. A high external pressure may also increase the resistance to gas expansion inside the particle. However, as more low-molecular-weight volatiles are retained in the residue at high pressure, the fluidity of the residue is enhanced ${ }^{21}$. This effect increases the potential of the particle to swell, due to the decrease in the resistance of the shell resulting from the increase in the fluidity of the residue. Therefore the overall effect of pressure on the char structure depends on the trade-off between these two effects ${ }^{18}$.

Gasification reactivity. Char morphology and microstructure are of particular importance to the study of high-temperature gasification rates. Fig. 4 shows the evolution of char reactivity versus carbon conversion during the steam gasification of the chars obtained from the SA coal. It can be appreciated from this figure that the higher the pyrolysis pressure, the faster the reactivity. No significant differences are found between chars SA1000-1 and SA1000-5. However, in the case of SA1000-10 and SA1000-20 the differences become more evident as they are more reactive than the other chars.

A parameter that is commonly used to compare the gasification reactivities of different fuels is the reactivity index, $R$, which is defined as $R=0.5 / \tau_{0.5}$, where $\tau_{0.5}$ represents the time required to reach $50 \%$ of carbon conversion. Fig. 5 shows a linear correlation between the reactivity indices of the SA chars and pyrolysis pressure. In this figure the micropore surface area of the 
chars is also plotted versus the pyrolysis pressure, showing a linear increase in micropore surface area with pyrolysis pressure and, therefore, with char reactivity under steam.

\subsection{Effect of pyrolysis temperature}

Thermoplastic properties and maceral effect on particle morphology. Thermal treatment can exert a considerable influence on the chemical composition and physical structure of the resultant $\operatorname{char}^{34}$. In our study, the bituminous coal SA was devolatilised at three different temperatures 800,900 and $1000{ }^{\circ} \mathrm{C}$, at a pressure of $20 \mathrm{~atm}$. The calculated heating rate for all the samples was around $5000{ }^{\circ} \mathrm{C} \mathrm{s}^{-1}$. The increase in the devolatilisation temperature produced a slight decrease in volatile matter, oxygen, hydrogen and nitrogen contents, but an increase in the carbon content (Table 2), similar to the results of other authors ${ }^{34}$. The helium density rose, as a consequence of the release of volatile matter and the increase in ash content, by a factor of $1.31,1.41$ and 1.45 for the chars obtained at 800,900 and $1000{ }^{\circ} \mathrm{C}$, respectively (Table 2). As in the case of the chars generated at different pressures, the bulk density of the chars obtained at the three temperatures are significantly lower than that of the raw coal. This decrease reached values of 45.8, 50.5 and $51.3 \%$, for the chars obtained at 800,900 and $1000{ }^{\circ} \mathrm{C}$, respectively.

The SEM micrographs of the chars obtained from coal SA pyrolysed at 20 atm and temperatures of 800,900 and $1000{ }^{\circ} \mathrm{C}$ are shown in Fig. 2. and their cross-sections in Fig. 3. The SA800-20 and SA900-20 chars exhibit the two main types of particles (essentially vitrinite- and inertinite-derived) present also in the chars SA1000-5, SA1000-10 and SA100020. Vitrinite-derived material from SA800-20 and SA900-20 appear to have thicker walls compared to the chars obtained at $1000^{\circ} \mathrm{C}$ (Figure 3). This could be the reason for the 800-900 ${ }^{\circ} \mathrm{C}$ char particles fragmenting to a lesser extent than those of the $1000{ }^{\circ} \mathrm{C}$ chars. This is in agreement with Griffin et al. ${ }^{35}$ who observed some structural collapse and particle fragmentation during the pyrolysis of bituminous coals above $900{ }^{\circ} \mathrm{C}$. In accordance with the findings of other authors ${ }^{5,36}$, the morphological differences between the chars obtained in the temperature range $800-1000{ }^{\circ} \mathrm{C}$ at elevated pressure $(20 \mathrm{~atm})$ were not significant.

Gasification reactivity. The influence of the pyrolysis temperature on reactivity during the steam gasification of the chars obtained at a pressure of 20 atm is shown in Fig. 4. An increase in reactivity with decreasing pyrolysis temperature is observed; char SA800-20 is the most reactive, followed by SA900-20 and SA1000-20. The $R$ values for these chars are 5.66, 5.85 
and $6.44 \mathrm{~h}^{-1}$, respectively. The same behaviour was observed in a previous work, with a decrease in char reactivity at higher pyrolysis temperatures ${ }^{37}$. As mentioned above, temperature treatment has a considerable influence on the resulting char structure. In particular, it removes heteroatoms and dislocations in the crystalline structure which are believed to give rise to the active sites on the surfaces. Char deactivation also occurs as a result of the realignment of the coal layer planes ${ }^{34,38,39}$.

The biggest differences in char reactivity were observed in the first stages of gasification, 5$20 \%$. However, during the course of the gasification, these differences gradually diminished until they reached the same reactivity values at around $60 \%$ of carbon conversion. This behaviour may be due to the fact that the high activity sites present in the chars obtained at lower devolatilisation temperatures are preferentially removed by $\mathrm{H}_{2} \mathrm{O}_{\mathrm{v}}$ in chemicallycontrolled gasification or annealed into less active sites, whereas the active sites with a lower reactivity remain in the residual char. If the gasification temperature is high enough, the char undergoes a process of annealing in competition with gasification. As gasification proceeds the amount of active sites and their reactivity toward $\mathrm{H}_{2} \mathrm{O}_{\mathrm{v}}$ tend to be the same and, as a result, the difference in char reactivities levels off and finally vanishes ${ }^{38,39}$.

\subsection{Effect of coal rank}

Thermoplastic properties and maceral effect on particle morphology. Char morphology is generally a function of parent coal rank, parent coal petrography, and devolatilisation conditions $^{27,28,40}$. In the present work, five coals from lignite to semi-anthracite with different petrographic compositions (see Table 1) were devolatilised at $1000^{\circ} \mathrm{C}$ and at pressures of 1 and $20 \mathrm{~atm}$. As can be seen from Table 2 the helium density of the chars increases, as a consequence of the evolution of the volatile matter and the increase in ash content. Bulk density has different effects on the chars depending on the rank of the parent coal. Thus, in the case of the LT chars the bulk density decreases by 23.0 and $31.5 \%$, for the 1 and 20 atm chars, respectively. The bulk density of the chars produced from the semi-anthracite, HV, are hardly modified at all, while the chars from the bituminous coals (DI, DT and SA) experience the highest bulk density reductions, especially so the 20 atm chars. This behaviour may have been due to the greater degree of swelling experienced by the bituminous coals.

The morphology and the physical structure of the char particles after devolatilisation were found to be dependent on coal rank and petrography. Fig. 6 shows the SEM images of the chars produced at $1000{ }^{\circ} \mathrm{C}$ and at pressures of 1 and $20 \mathrm{~atm}$. The fact that different structures are 
observed in the coal particles is attributed to differences in plastic behaviour which is determined by the coal rank and to variations in their maceral composition. Generally speaking, particles containing liptinites or vitrinites generate porous chars while those with inertinites generate relatively dense char structures ${ }^{19}$. The effect of coal rank on char structure can be more easily observed in the vitrinite, which is the most homogeneous maceral group whose properties vary gradually with coal rank. Low rank coals such as lignites usually generate rather massive chars in which the carbonaceous material shows signs of degassing in the form of small bubbles (Fig. 7). Lignites typically devolatilise yielding low molecular weight molecules. Thus degassing bubbles do not have the chance to grow and coalesce to produce any swelling. This is in accordance with the absence of a softening regime during the pyrolysis of the lignites ${ }^{41}$. As can be seen in Fig. 6, very few changes occurred in the external morphology of the lignite (LT) char particles at 1 and 20 atm. In fact, they have a similar external angular shape to the parent coal, despite the large amount of volatiles lost. Fig. 7 shows the optical images of the cross-sections of LT1000-1 and LT1000-20 which are very similar. The particles of both chars present an isotropic optical texture and certain porosity. However in LT1000-20 the pores are larger and more rounded than in LT1000-1.

An increase in coal rank, up to low volatile bituminous, implies an increase in aromaticity and fusibility ${ }^{27}$. Some of these coals exhibit thermoplastic behaviour when heated and melt to form a highly viscous liquid. Usually, the bituminous coals with a carbon content in the range of 8192\% exhibit maximum fluidity. Consequently, the proportion of Fusinoid particles usually decreases, while the proportion of Tenuisphere, Crassisphere and Tenuinetwork particles increases $^{27,28,42}$.

Regarding the three bituminous coals, DI (lvb), DT (hvb) and SA (hvb), it can be seen in Fig. 6 that the char particles obtained at 1 atm (DT1000-1 and DI1000-1) are smaller than those obtained at 20 atm (DT1000-20 and DI1000-20), as occurred in the case of coal SA at different pressures (cf. Fig. 2). However, the chars produced at atmospheric pressure show external differences. Thus, DI1000-1 has a more spherical shape and more rounded edges than DT10001 and SA1000-1. This could be due to the higher vitrinite content of coal DI (74.3\%) compared to coals DT $(41.5 \%)$ and SA (33.6\%). The vitrinite-containing particles from bituminous coals commonly produce cenospheric chars ${ }^{19}$. From our observations, it seems likely that the higher the vitrinite content, the higher the number of spherical particles. The differences observed at atmospheric pressure are more evident in the chars obtained at elevated pressure. DT1000-20 
and DI1000-20 exhibit considerable swelling, as can be seen in Fig. 6, and have larger holes or voids on their surface than SA1000-20 (cf. Fig. 2).

With regard to maceral composition, coals DT and SA have high inertinite contents of 56.4 and $60.9 \%$, respectively. Coal DT shows a devolatilisation behaviour similar to that of coal SA, but with some differences. As is typical of many Chinese coals ${ }^{43}$ during the coalification process, the inertinite in DT underwent a smooth process of oxidation as a result of which the semifusinite (very abundant in this coal) retained significant plastic properties. This explains the higher porosity of the DT particles developed during their pyrolysis (Fig. 7), compared to the inertinites in other coals, such as coal SA (cf. Fig. 3), in which the inertinite-derived particles tended to be more massive. Vitrinite behaved similarly in coals DT and SA as expected in view of their similar reflectance values, yielding highly swollen isotropic cenospheric particles, the most significant difference being the mass distribution within the particles, which tended to be more peripheral in SA (cf. Fig. 3 and 7). DT1000-20 vitrinitederived particles underwent extensive swelling, as can be seen in Fig. 7, which shows a swollen particle with thin walls and large voids from pore collapse. In addition, some of the swollen thin-walled particles fragmented, as occurred with coal SA at elevated pressures (cf. Fig. 3).

The low volatile bituminous coal, DI, has the lowest inertinite content (25.7\%) compared to the other bituminous coals, SA and DT (Table 1). Its inertinite-derived particles present a massive and isotropic appearance, irrespective of the pyrolysis pressure, leading to Inertoid, Fusinoid and even Solid char types. Its vitrinite-derived particles, unlike coals SA and DT, show an exclusively anisotropic optical texture. Due to its thermoplastic behaviour, char particles melt and form ordered aromatic domains, which is characteristic of some high rank coals. The char particles obtained at atmospheric pressure, DI1000-1, have quite thick walls and very few pores of a large size, its particles being of the Mesosphere type (Fig. 7). In contrast, the char vitrinite-derived particles in DI1000-20 experience substantial swelling, as occurred in coals SA and DT. These particles present a large number of pores and very thin walls, and could be classified as Tenuinetwork. Fragmentation in DI appears to be a rather limited phenomenon even at high pressures, possibly due to the greater resistance of the walls formed by wellordered aromatic domains.

Generally anthracites are considered to exhibit limited or negligible thermoplastic behaviour. Under typical combustion conditions, with high heating rates, the plastic interval is enhanced ${ }^{44}$ and therefore semianthracites and some anthracites have been shown to retain a certain 
plasticity ${ }^{45}$. In our study, the semianthracite particles essentially retain their structure during devolatilisation, the main differences with the parent coal particles being the enhanced reflectance and anisotropy (better structural order) and the generation of cleats or fissures through which volatiles could have escaped (Fig. 6 and 7). These cleats, often S-shaped and parallel to the bedding plane, are more frequent in the HV1000-20 char than in the HV1000-1 char (Fig. 7). The vitrinite-derived particles in the HV anthracite present anisotropy due not to thermoplasticity, but to an enhancement of the anisotropy inherent in anthracites. This is due to burial perpendicular to the bedding and the ordering of the internal structure. This anisotropy appears as different monochrome shades of pink and results from the observation of randomly cut sections of particles with a given homogeneous orientation (stacking parallel to the bedding plane).

The largest differences in morphology between the chars obtained at atmospheric and at high pressure have been observed for the bituminous coal chars (Figs. 2-3, 6-7). For the three bituminous coal chars, the vitrinite-derived particles enhanced their swelling behaviour at high pressure, as shown by the larger size of the particles and the thinner char walls ${ }^{6}$. In addition, the observation of both topographic SEM images and optical images from cross sections indicates that the vitrinite-derived particles are the ones more sensitive to the effect of pressure. It is not unexpected that the vitrinite passes through a metaplast stage during heating, and it would be then the material most affected by the higher residence time of the volatiles within the particles, and the tar cracking provoked by pressure. A similar effect could be expected for the inertinite-derived material although, due to its inherent heterogeneity, is more difficult to systematise.

\section{Conclusions}

The effect of pressure and temperature on char morphology and structure during the devolatilisation of different rank coals was studied. It was found that pyrolysis pressure had a significant impact on the structure and morphology of the resultant char particles, this effect being especially evident in the case of the bituminous coals. An increase in devolatilisation pressure led to greater swelling, and produced larger particles with thinner pore walls. In the case of the high volatile bituminous coal SA, in the range of pressures studied (1 to $20 \mathrm{~atm}$ ), fragmentation occurred during devolatilisation, with an increase in the amount of fragments in the char samples subjected to higher pressures. At $1000{ }^{\circ} \mathrm{C}$ the thickness of the wall char decreased considerably, which may also have contributed to particle fragmentation. 
As regards coal rank, the vitrinite particles of the bituminous coals were modified to the greatest extent, experiencing substantial swelling during devolatilisation at high pressure, whereas those of the lignite retained their external shape and those of semi-anthracite experienced very limited transformation.

Char reactivity increased with the devolatilisation pressure. In contrast, an increase in devolatilisation temperature led to a decrease in char reactivity. This behaviour may have been due to thermal annealing which caused a realignment of the coal layer planes and resulted in the deactivation of the char; as a consequence, access of steam to the active sites was reduced.

\section{References}

(1) Carpenter, A. M. Poligeneration from coal; IEA Clean Coal Centre, London, UK, 2008.

(2) Harris, D. J.; Patterson, J. H. Aust. Inst. Energy 1995, 13-22.

(3) Takematsu, T.; Maude, C. Coal gasification for IGCC power generation; IEA Coal Research, Gemini House: London, 1991.

(4) Alonso, M. J. G.; Borrego, A. G.; Alvarez, D.; Parra, J. B.; Menéndez, R. J. Anal. Appl. Pyrol. 2001, 58, 887-909.

(5) Matsuoka, K.; Akiho, H.; Xu, W.-C.; Gupta, R.; Wall, T. F.; Tomita, A. Fuel 2005, 84, 6369.

(6) Wall, T. F.; Liu, G.-S.; Wu, H.-W.; Roberts, D. G.; Benfell, K. E.; Gupta, S.; Lucas, J. A.; Harris D. J. Progr. Energ. Combust. 2002, 28, 405-453.

(7) Yu, J.; Harris, D.; Lucas, J.; Roberts, D.; Wu, H.; Wall, T. Energy Fuels 2004, 18, 13461353.

(8) ASTM Standard D0388, 2005. Standard Classification of Coals by Rank. ASTM International, West Conshohocken, PA. doi:10.1520/D0388-05. www.astm.org.

(9) van Krevelen, D. W. Coal: typology, physics, chemistry, constitution; Elsevier: Amsterdam, 3rd rev. ed. 979 p., 1993.

(10) Fermoso, J.; Arias, B.; Plaza, M. G.; Pevida, C.; Rubiera, F.; Pis, J. J.; García-Peña, F.; Casero, P. Fuel Process. Technol. 2009, 90, 926-932.

(11) Dubinin, M. M.; Astakhov, V. A. Ad. Chem. Ser. 1971, 102, 69-85.

(12) Mitchell, R. E.; Campbell, P. A.; Ma, L. Coal and biomass char reactivity. 2003 GCEP Technical Report.

(13) Pis, J. J.; de la Puente, G.; Fuente, E.; Moran, A.; Rubiera, F. Thermochim. Acta 1996, 279, 93-101.

(14) Rubiera, F.; Arenillas, A.; Fuente, E.; Miles, N.; Pis, J. J. Powder Technol. 1999, 105, 351-356.

(15) Arenillas, A.; Rubiera, F.; Pis, J. J.; Jones, J. M.; Williams, A. Fuel 1999, 78, 1779-1785.

(16) Taylor, G. H.; Teichmüler, M.; Davis, A.; Littke, R.; Diessel, C. F. K. Organic petrology; Gebrüder Bornträger: Berlin-Sttutgart, Germany, 1998.

(17) Borrego, A.G.; Marbán, G.; Alonso, M. J. G.; Alvarez, D.; Menéndez, R. Energy Fuels 2000, 14, 117-126.

(18) Wu, H.; Bryant, G.; Benfell, K.; Wall, T. Energy Fuels 2000, 14, 282-290.

(19) Yu, J.; Lucas, J. A.; Wall, T. F. Progr. Energ. Combust. 2007, 33, 135-170.

(20) Shan, G. A Comprehensive Model for Coal Devolatilisation, PhD Thesis, Chemical Engineering Department, The University of Newcastle, Australia (2000). 
(21) Kaiho, M.; Toda, Y. Fuel 1979, 58, 397-398.

(22) Lee, C. W.; Scaroni, A. W.; Jenkins, R. G. Fuel 1991, 70, 957-965.

(23) Solomon, P. R.; Fletcher, T. H. P. Combust. Inst. 1994, 463-474.

(24) Khan, M. R.; Jenkins, R. G. Fuel 1986, 65, 725-731.

(25) Street, P. J.; Weight, R. P.; Lightman, P. Fuel 1969, 48, 343-365.

(26) Jones, R. B.; Morley, C.; McCourt, C. B. Maceral effects on the morphology and combustion of coal char. Proceedings of 1985 International Conference on Coal Science, Pergammon Press, Sydney, Australia, p. 669, 1985.

(27) Bailey, J. G.; Tate, A.; Diessel, C. F. K.; Wall, T. F. Fuel 1990, 69, 225-239.

(28) Cloke, M.; Lester, E. Fuel 1994, 73, 315-320.

(29) Alvarez, D.; Borrego, A. G.; Menéndez, R. Fuel 1997, 76, 1241-1248.

(30) Lester, E.; Alvarez, D.; Borrego, A. G.; Valentim, B.; Flores, D.; Clift, D. A.; Rosenberg, P.; Kwiecinska, B.; Barranco, R.; Petersen, H. I.; Mastalerz, M.; Milenkova, K. S.; Panaitescu, C.; Marques, M. M.; Thompson, A.; Watts, D.; Hanson, S.; Predeanu, G.; Misz, M.; Wu, T. Int. J. Coal Geol. 2010, 81, 333-342.

(31) ICCP (International Committee for Coal and Organic Petrology) 1996 http://www.iccop.org/index.php?id=45, date:06.18.2010.

(32) Diessel, C. F. K. Coal-bearing depositional systems; Springer: Berlin, 1992.

(33) Benfell, K. E.; Liu, G.-S.; Roberts, D.; Harris, D. J.; Lucas, J. A.; Bailey, J. G.; Wall, T. F. Proc. of the combust. Inst. 2000, 28, 2233-2241.

(34) van Heek, K. H.; Mühlen, H.-J. Fuel Process. Technol. 1987, 15, 113-133.

(35) Griffin, T. P.; Howard, J. B.; Peters, W. A. Fuel 1994, 73, 591-601.

(36) Berkowitz, N. The chemistry of coal, coal science and technology; Elsevier: Amsterdam, 1985; pp. 249-253.

(37) Fermoso, J.; Stevanov, C.; Moghtaderi, B.; Arias, B.; Pevida, C.; Plaza, M. G.; Rubiera, F.; Pis, J. J. J. Anal. Appl. Pyrol. 2009, 85, 287-293.

(38) Senneca, O.; Russo, P.; Salatino, P.; Masi, S. Carbon 1997, 35, 141-151.

(39) Zhang, S.-Y.; Lu, J.-F.; Zhang, J.-S.; Zhang, Yue, G.-X. Energy Fuels 2008, 22, 32133221.

(40) Bend, S. L.; Edwards, I. A. S.; Marsh, H. Fuel 1992, 71, 493-501.

(41) Zeng, D.; Fletcher, T. H. Energy Fuels 2005, 19, 1828-1838.

(42) Oka, N.; Murayama, T.; Matsuoka, H.; Yamada, S.; Shinozaki, S.; Shibaoka, M.; Thomas, C. G. Fuel Process. Technol. 1987, 15, 213-224.

(43) de Sousa e Vasconcelos, L. Int. J. Coal Geol. 1999, 40, 27-58.

(44) Saxena, S.C. Progr. Energ. Combust.1990, 16, 55-94.

(45) Borrego, A. G.; Martín, A. J. Int. J. Coal Geol. 2010, 81, 301-308. 


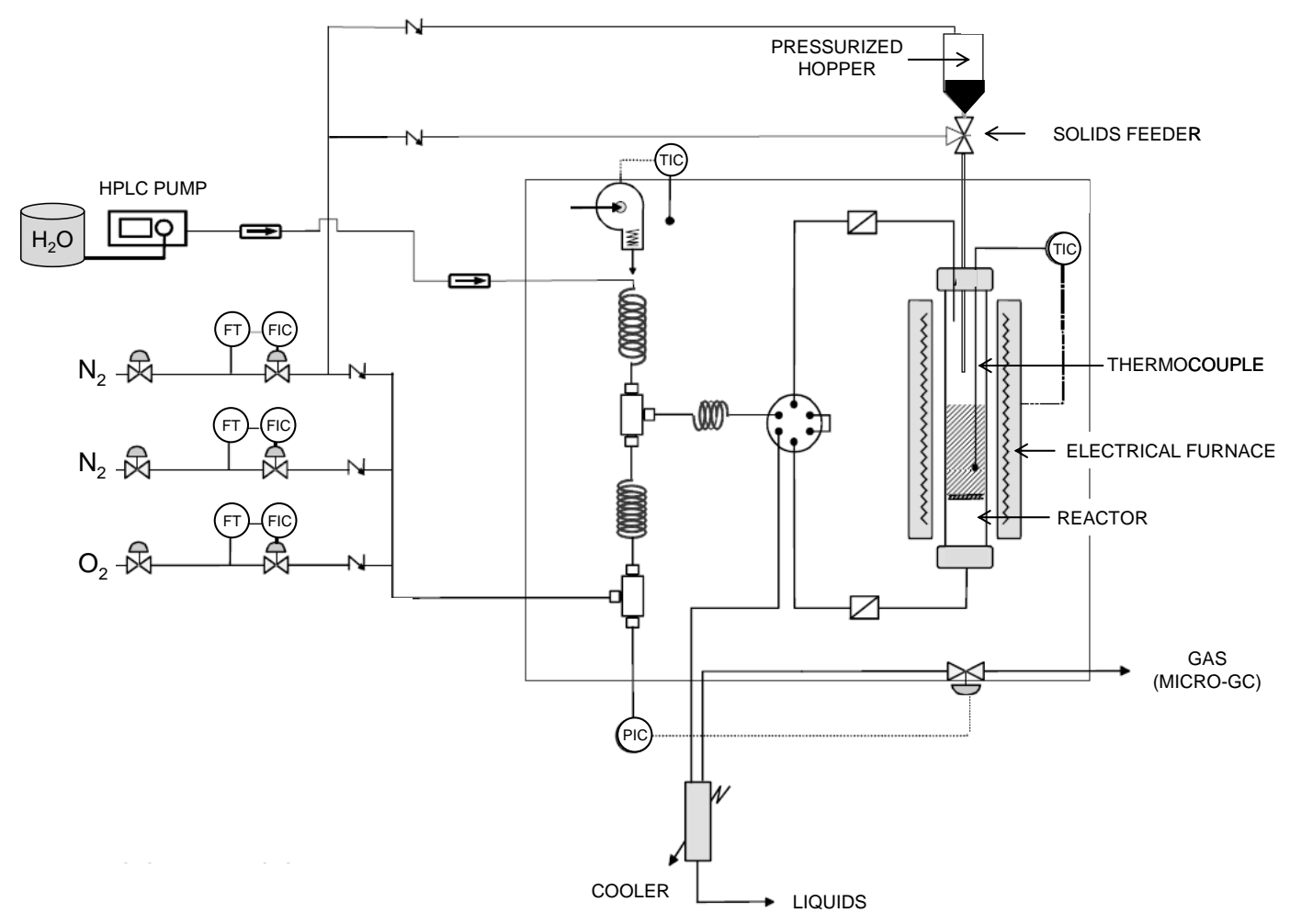

Fig. 1. Flow diagram of the experimental devolatilisation device. 




Fig. 2. SEM images of the SA char particles obtained under different pressure and temperature conditions. 

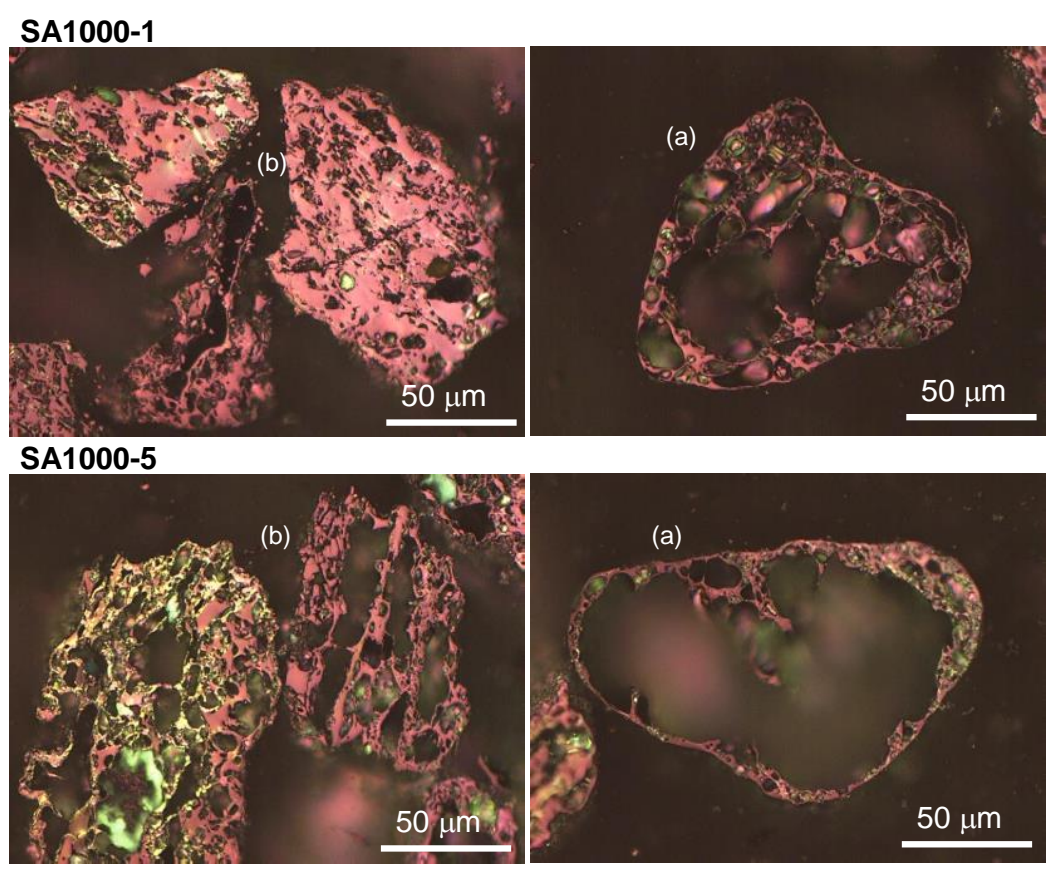

SA1000-10

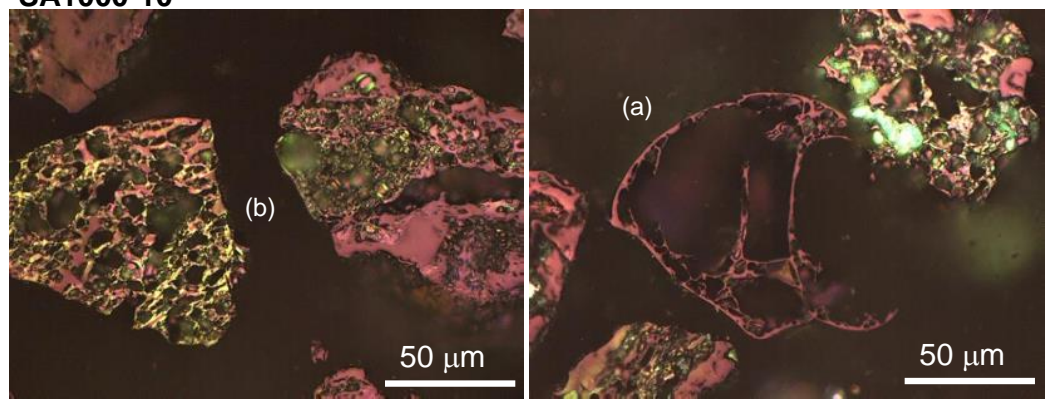

SA1000-20
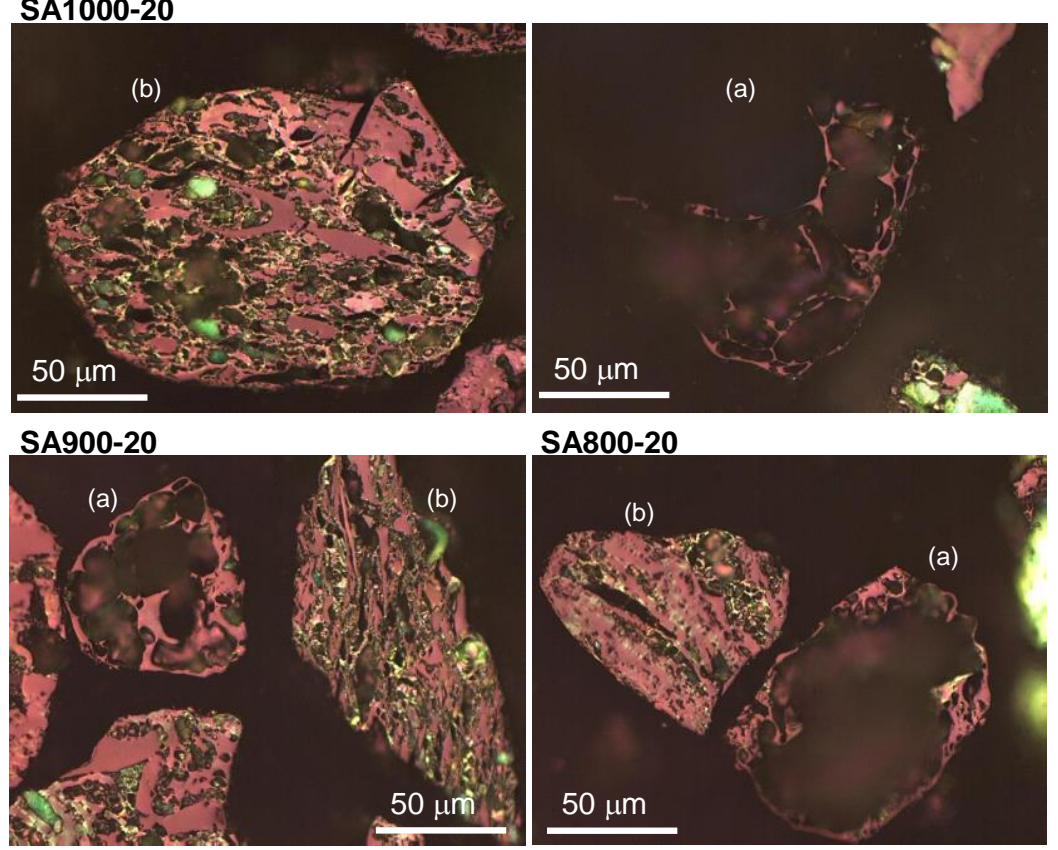

SA800-20

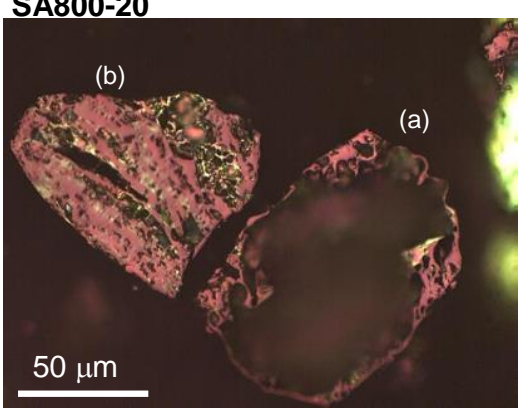

Fig. 3. Optical photomicrographs of the cross-sections of vitrinite- (a) and inertinite-derived (b) SA chars obtained at different pressure and temperature conditions. Images taken under polarized light with $1 \lambda$ retarder plate. 


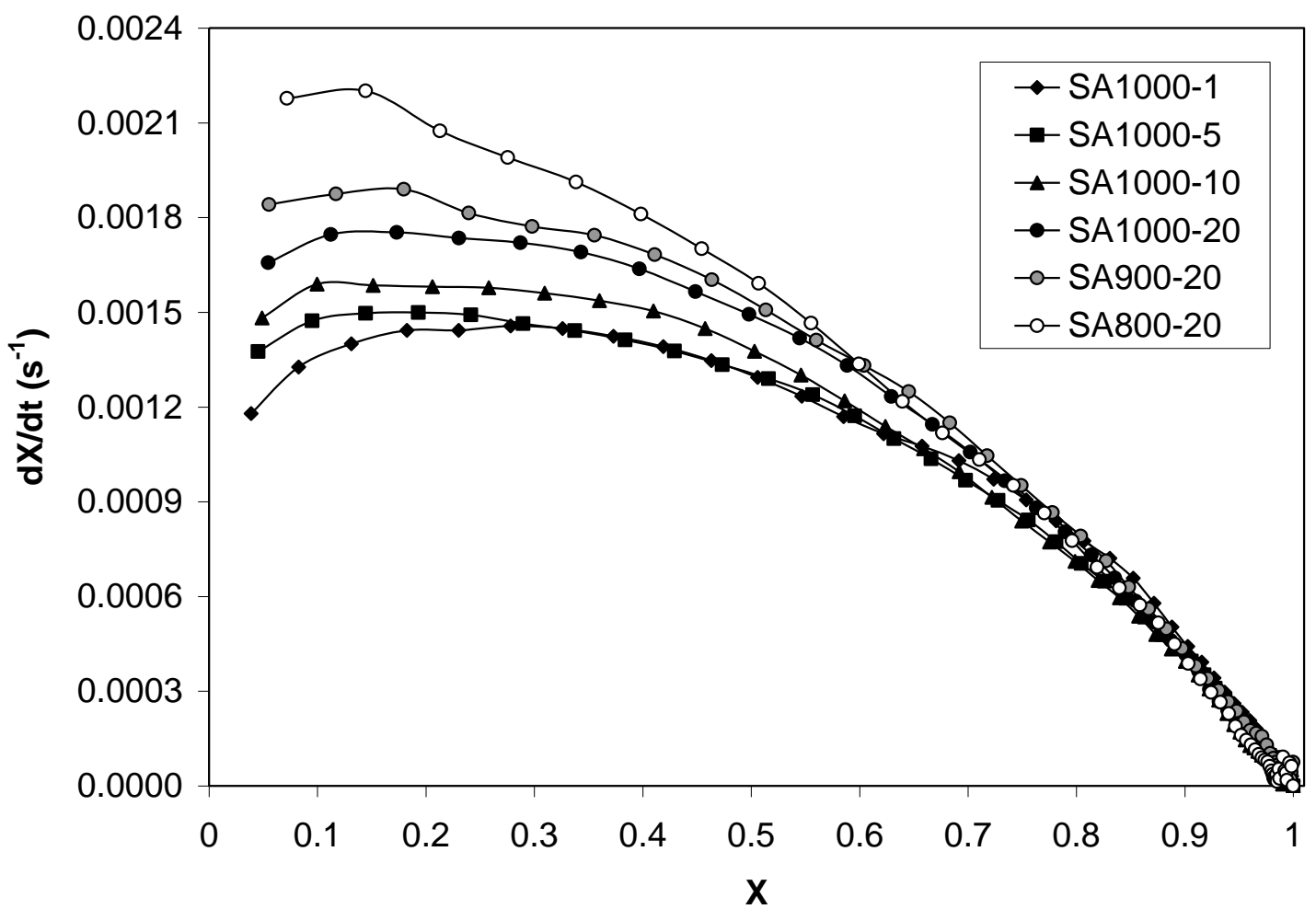

Fig. 4. Influence of pyrolysis conditions (pressure and temperature) on char reactivity during the steam gasification at $1000{ }^{\circ} \mathrm{C}\left(70 \% \mathrm{~N}_{2}-30 \% \mathrm{H}_{2} \mathrm{O}_{\mathrm{v}}\right)$ of the SA chars. 


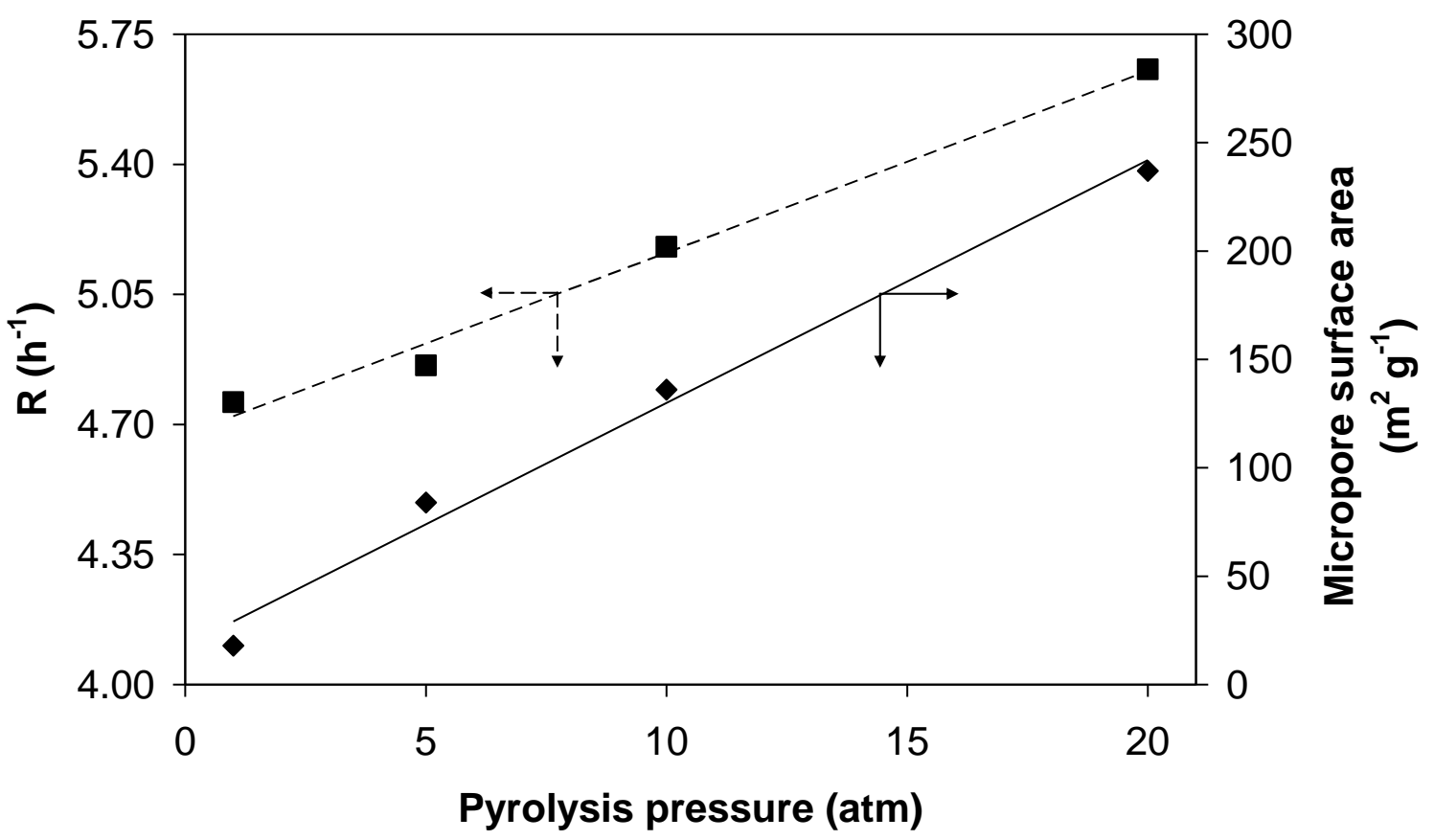

Fig. 5. Reactivity index and micropore surface area of SA coal chars as a function of pyrolysis pressure. 

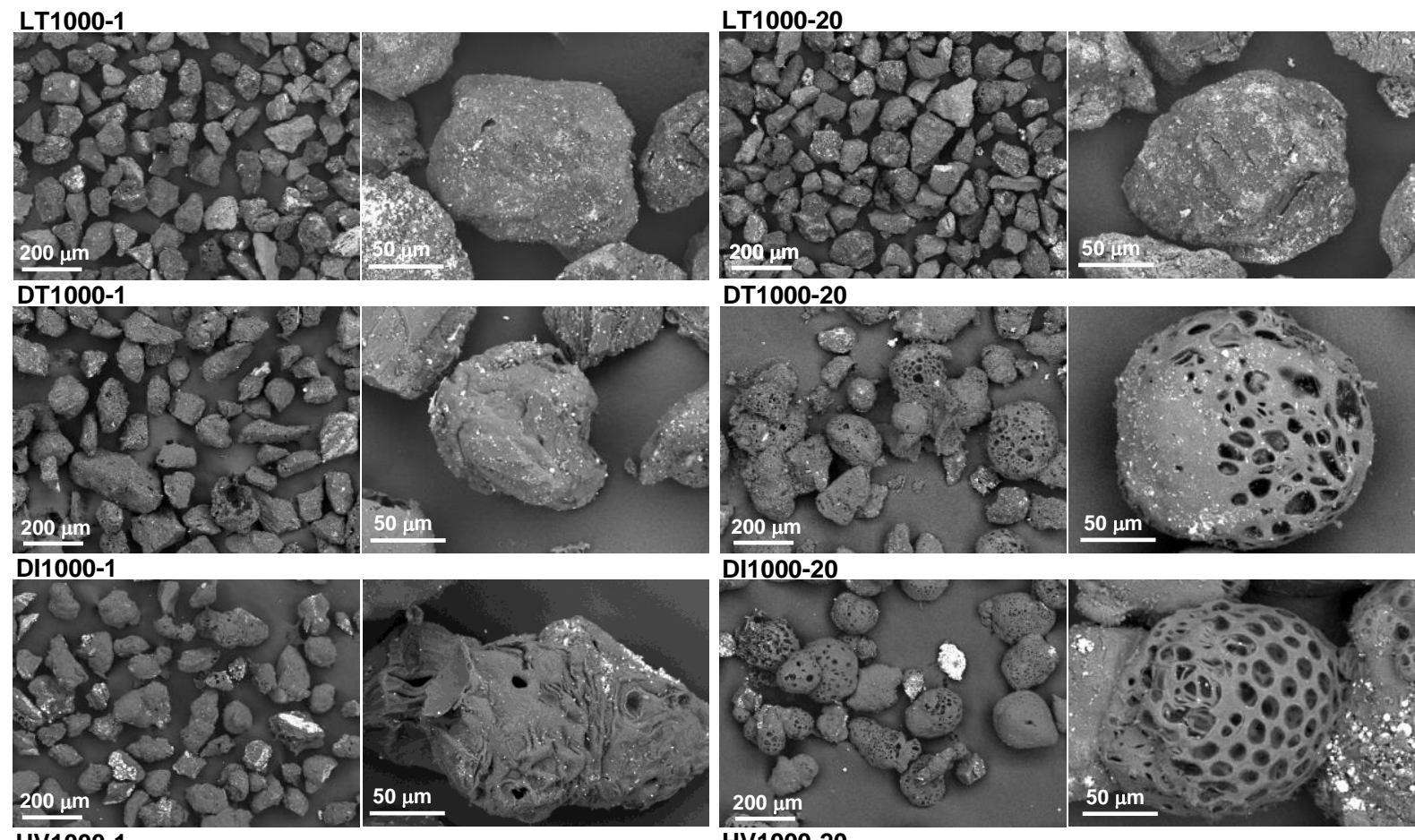
DT1000-20
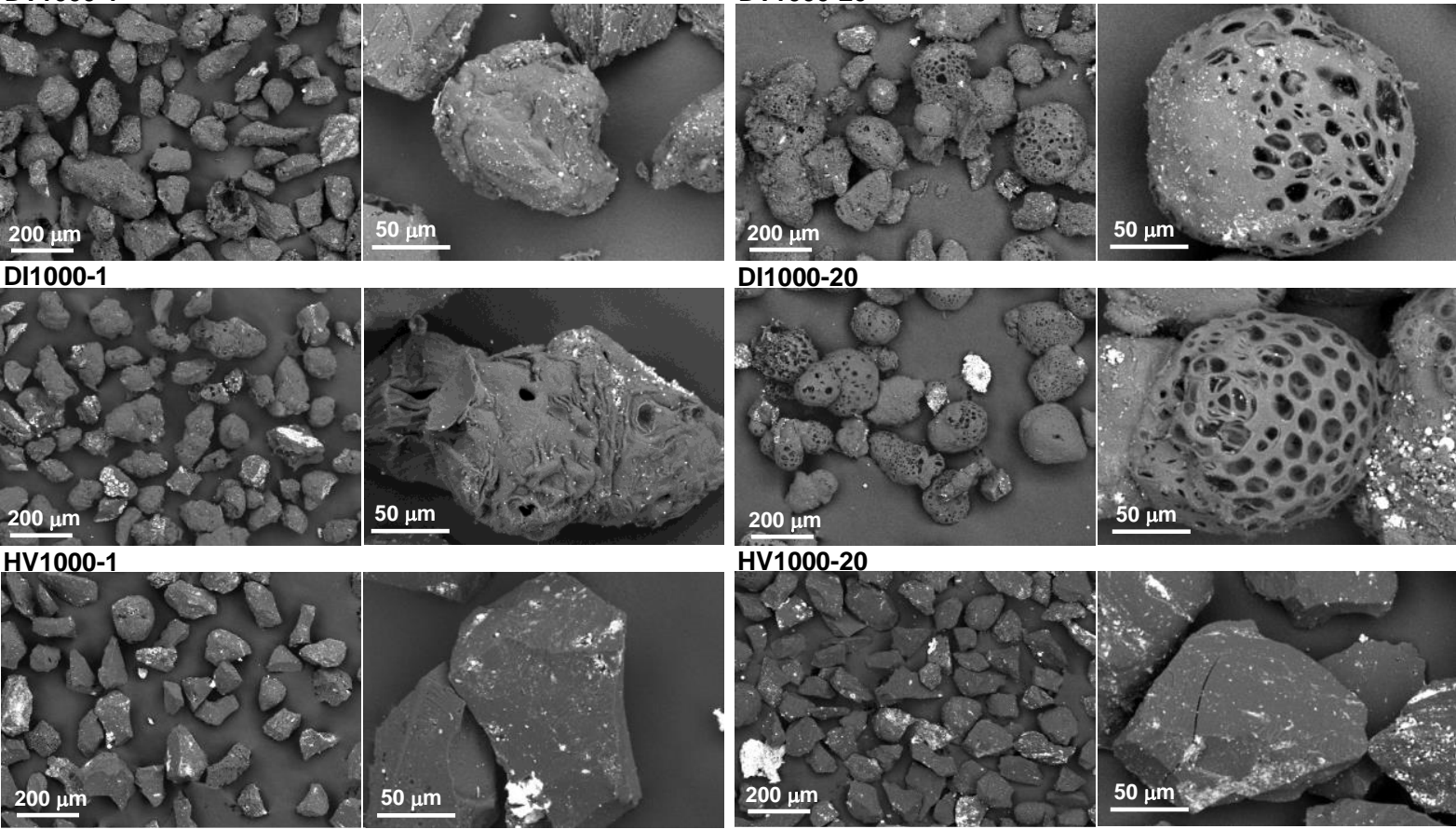

DI1000-20
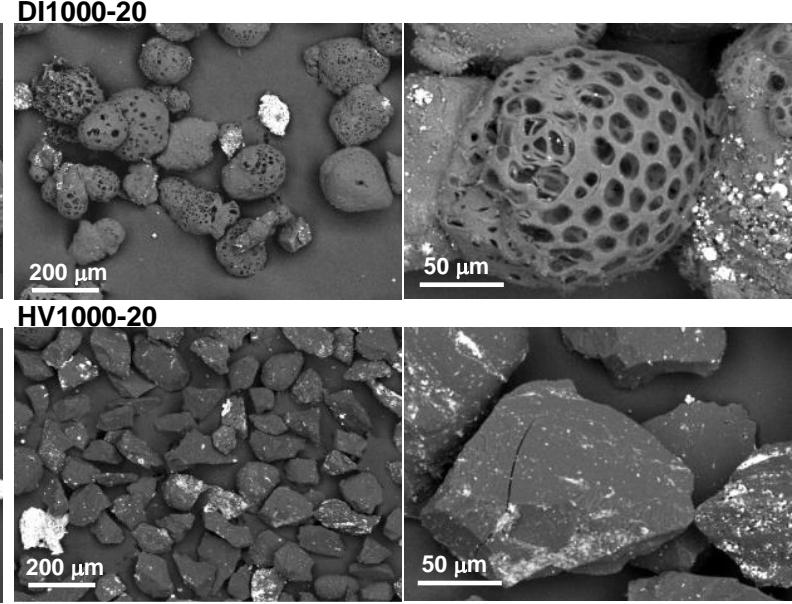

Fig. 6. SEM images of the char particles obtained by devolatilisation of coals LT, DT, DI and $\mathrm{HV}$ at $1000{ }^{\circ} \mathrm{C}$, and at pressures of 1 and 20 atm. 


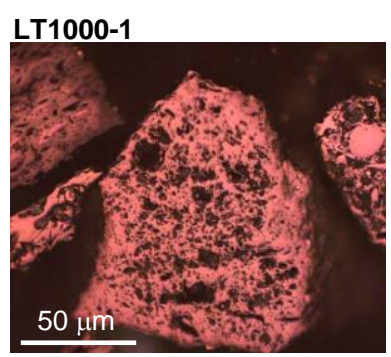

DT1000-1

LT1000-20

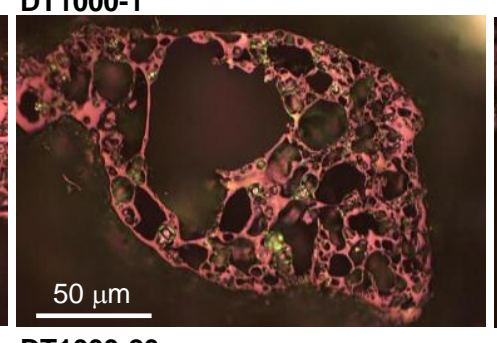

Dl1000-1

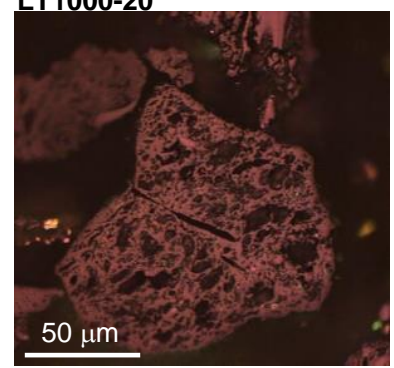

DT1000-20

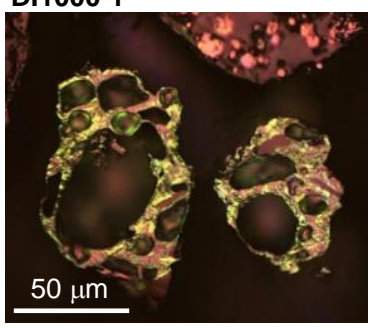

HV1000-1

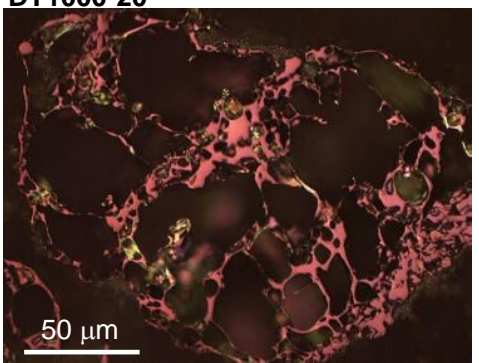

DI1000-20

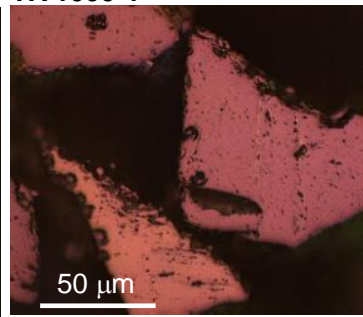

HV1000-20
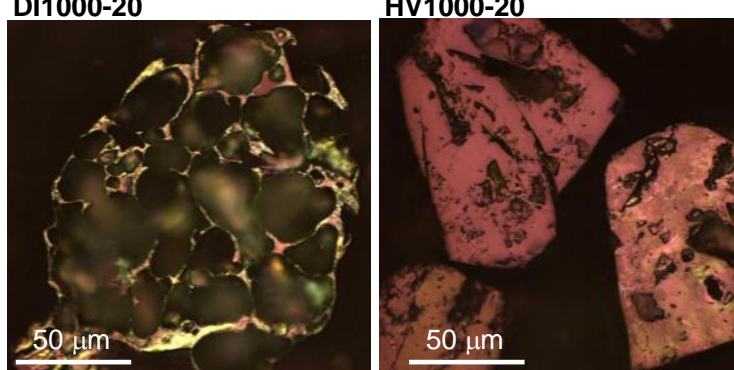

Fig. 7. Optical photomicrographs of the char particle cross-sections obtained by the devolatilisation of coals LT, DT, DI and HV at $1000{ }^{\circ} \mathrm{C}$ and at pressures of 1 and $20 \mathrm{~atm}$. Images taken under polarized light with a $1 \lambda$ retarder plate. 
Table 1. Chemical and petrographic analyses of the raw coals

\begin{tabular}{|c|c|c|c|c|c|c|}
\hline \multicolumn{2}{|l|}{ Sample } & LT & DT & SA & DI & $\mathrm{HV}$ \\
\hline \multicolumn{2}{|l|}{ Origin } & Spain & China & South Africa & Spain & Spain \\
\hline \multicolumn{2}{|l|}{ Rank* } & lig & hvb & hvb & $1 \mathrm{vb}$ & $\mathrm{sa}$ \\
\hline \multicolumn{7}{|c|}{ Proximate Analysis** } \\
\hline \multicolumn{2}{|c|}{ Moisture content (wt.\%) } & 3.5 & 1.2 & 2.0 & 1.2 & 1.1 \\
\hline \multicolumn{2}{|c|}{ Ash (wt.\%, db) } & 18.2 & 11.7 & 15.4 & 4.3 & 8.7 \\
\hline \multicolumn{2}{|c|}{ V.M. (wt.\%, db) } & 38.9 & 28.5 & 26.7 & 16.1 & 10.5 \\
\hline \multicolumn{2}{|c|}{ F.C. $(w t . \%, d b)^{* * *}$} & 42.9 & 59.8 & 57.9 & 79.6 & 80.8 \\
\hline \multicolumn{7}{|c|}{ Ultimate Analysis (wt.\%, daf) ** } \\
\hline \multicolumn{2}{|l|}{$\mathrm{C}$} & 57.5 & 81.2 & 81.4 & 86.4 & 87.7 \\
\hline \multicolumn{2}{|l|}{$\mathrm{H}$} & 4.9 & 5.1 & 5.0 & 4.3 & 3.7 \\
\hline \multicolumn{2}{|l|}{$\mathrm{N}$} & 0.5 & 1.1 & 2.4 & 1.9 & 2.8 \\
\hline \multicolumn{2}{|l|}{ S } & 5.3 & 0.8 & 0.6 & 1.8 & 1.0 \\
\hline \multicolumn{2}{|l|}{$\mathrm{O} * * *$} & 31.8 & 11.8 & 10.6 & 5.6 & 4.8 \\
\hline \multicolumn{2}{|c|}{ Helium density $\left(\mathrm{g} \mathrm{cm}^{-3}\right)$} & 1.618 & 1.425 & 1.457 & 1.411 & 1.443 \\
\hline \multicolumn{2}{|c|}{ Bulk density $\left(\mathrm{g} \mathrm{cm}^{-3}\right)$} & 0.832 & 0.752 & 0.760 & 0.774 & 0.799 \\
\hline \multicolumn{7}{|c|}{ Maceral Analysis $(\%, \mathrm{mmf})$} \\
\hline \multicolumn{2}{|l|}{ Vitrinite } & 80.8 & 41.9 & 33.7 & 74.3 & 96.1 \\
\hline \multicolumn{2}{|l|}{ Liptinite } & 2.1 & 1.7 & 5.4 & 0.0 & 0.0 \\
\hline \multirow{4}{*}{ Inertinite } & Semi-fusinite & 15.3 & 53.6 & 58.5 & 17.6 & 2.6 \\
\hline & Fusinite & 1.3 & 2.8 & 2.4 & 7.2 & 1.3 \\
\hline & Other inertinites & 0.5 & 0.0 & 0.0 & 0.9 & 0.0 \\
\hline & Total & 17.1 & 56.4 & 60.9 & 25.7 & 3.9 \\
\hline \multicolumn{2}{|c|}{ Mean vitrinite reflectance $(\%)$} & 0.42 & 0.60 & 0.58 & 1.66 & 2.45 \\
\hline
\end{tabular}

$\mathrm{db}$ : dry basis; daf: dry and ash free bases; mmf: mineral matter free basis.

* lig: lignite; lvb: low volatile bituminous coal; hvb: high volatile bituminous coal; sa: semi-anthracite.

** The proximate analysis was conducted in a LECO TGA-601, and the ultimate analysis in a LECO CHNS-932.

*** obtained by difference. 
Table 2. Weight loss during pyrolysis, and proximate and ultimate analyses and densities of the coal chars

\begin{tabular}{|c|c|c|c|c|c|c|c|c|c|c|c|}
\hline \multirow{2}{*}{$\begin{array}{c}\text { Char } \\
\text { Sample }\end{array}$} & \multirow{2}{*}{$\begin{array}{c}\text { Weight } \\
\text { loss } \\
\text { (wt.\%, db) }\end{array}$} & \multicolumn{3}{|c|}{$\begin{array}{l}\text { Proximate Analysis } \\
\text { (wt. } \%, \mathrm{db})^{*}\end{array}$} & \multicolumn{5}{|c|}{ Ultimate Analysis (wt.\%, daf)* } & \multirow{2}{*}{$\begin{array}{l}\text { Helium } \\
\text { density } \\
\left(\mathrm{g} \mathrm{cm}^{-3}\right)\end{array}$} & \multirow{2}{*}{$\begin{array}{c}\text { Bulk } \\
\text { density } \\
\left(\mathrm{g} \mathrm{cm}^{-3}\right)\end{array}$} \\
\hline & & Ash & V.M. & F.C. $* *$ & $\mathrm{C}$ & $\mathrm{H}$ & $\mathrm{N}$ & $\mathrm{S}$ & $\mathrm{O} * *$ & & \\
\hline SA800-20 & 33.5 & 21.6 & 4.2 & 74.2 & 91.3 & 1.6 & 2.1 & 0.4 & 4.6 & 1.905 & 0.412 \\
\hline SA900-20 & 32.2 & 21.8 & 1.2 & 77.0 & 92.3 & 1.1 & 2.1 & 0.3 & 4.2 & 2.057 & 0.376 \\
\hline SA1000-20 & 32.9 & 22.5 & 1.2 & 76.3 & 94.3 & 0.8 & 1.7 & 0.2 & 3.0 & 2.111 & 0.370 \\
\hline SA1000-10 & 34.0 & 23.5 & 1.2 & 75.3 & 93.9 & 0.8 & 1.9 & 0.3 & 3.1 & 2.175 & 0.386 \\
\hline SA1000-5 & 32.1 & 20.5 & 1.4 & 78.1 & 92.4 & 1.1 & 2.1 & 0.3 & 4.1 & 2.077 & 0.418 \\
\hline SA1000-1 & 33.8 & 24.7 & 2.0 & 73.3 & 91.4 & 1.2 & 2.3 & 0.3 & 4.8 & 2.046 & 0.520 \\
\hline LT1000-1 & 48.7 & 30.8 & 2.6 & 66.6 & 86.3 & 0.6 & 0.6 & 10.5 & 2.0 & 2.264 & 0.641 \\
\hline LT1000-20 & 51.4 & 38.5 & 4.6 & 56.9 & 86.6 & 0.9 & 0.3 & 11.2 & 1.0 & 2.355 & 0.570 \\
\hline DT1000-1 & 34.3 & 16.8 & 1.7 & 81.5 & 94.9 & 0.8 & 1.0 & 0.5 & 2.8 & 2.025 & 0.488 \\
\hline DT1000-20 & 35.0 & 16.8 & 1.5 & 81.7 & 96.1 & 0.8 & 0.9 & 0.5 & 1.7 & 2.050 & 0.256 \\
\hline DI1000-1 & 18.9 & 8.5 & 1.1 & 90.4 & 94.2 & 0.7 & 1.4 & 1.9 & 1.8 & 1.984 & 0.506 \\
\hline DI1000-20 & 18.9 & 4.4 & 1.5 & 94.1 & 95.5 & 0.6 & 1.1 & 1.3 & 1.5 & 2.051 & 0.245 \\
\hline HV1000-1 & 12.0 & 10.4 & 1.1 & 88.5 & 92.5 & 1.0 & 2.0 & 0.8 & 3.7 & 1.976 & 0.834 \\
\hline HV1000-20 & 12.1 & 11.5 & 1.5 & 87.0 & 93.6 & 0.9 & 1.4 & 0.6 & 3.5 & 1.949 & 0.756 \\
\hline
\end{tabular}

db: dry basis; daf: dry ash free basis.

* The proximate analysis was conducted in a LECO TGA-601, and the ultimate analysis in a LECO CHNS-932.

** obtained by difference. 